\title{
PATTERN OF DENTAL OCCLUSION IN A POPULATION OF URHOBO SUBJECTS IN ABRAKA, NIGERIA
}

\author{
*Anibor, E. \\ *Department of Human Anatomy and Cell Biology, Faculty of Basic Medical Sciences, Delta State University, Abraka, Nigeria. \\ *Corresponding Author E-mail: eseovo2000@yahoo.com Phone: 08131617679 and 08180404966
}

\begin{abstract}
The closing order of superior and inferior teeth whilst chewing or at relaxation is termed dental occlusion. Literature exploration divulged want of information on dental occlusion among the Urhobos in Delta State, Nigeria. The endeavour of this work was to consider varied dental occlusion patterns and explore gender variation in dental occlusion patterns amongst the Urhobo tribal cluster in Abraka, Nigeria. Totality of 384 citizens (200 females and 184 males) who were within 15-30 years age set were engaged in this inquisition. The gender gap is a depiction of the male/female scattering in the appraised populace. Records on dental occlusion patterns were composed by having the subjects' bite, gulp saliva, occlude and open their mouths. The connexion of the upper and lower teeth was labelled as mild overbite, edge to edge bite, negative bite or severe overbite as specified by Eveleth in 1972. Inferential statistics were explored using chi-square by means of Statistical Package for the Social Sciences (SPSS), version 23 and significance level were determined by $\mathrm{p}<.05$. The dental occlusion patterns observed were mild overbite 168 (43.4\%), edge-edge bite $146(38.2 \%)$, severe overbite $70(18.4 \%)$ with no negative overbite 0 $(0 \%)$. The gender dissimilarity in dental occlusion pattern was not notable $(\mathrm{p}>.05)$. Mild overbite is preponderant and severe overbite is infrequent amid the Urhobos in Abraka, Nigeria.
\end{abstract}

Keywords: Dental, Nigeria, Occlusion, Pattern, Urhobos

LICENSE: This work by Open Journals Nigeria is licensed and published under the Creative Commons Attribution License 4.0 International License, which permits unrestricted use, distribution, and reproduction in any medium, provided this article is duly cited.

COPYRIGHT: The Author(s) completely retain the copyright of this published article.

OPEN ACCESS: The Author(s) approves that this article remains permanently online in the open access (OA) mode.

QA: This Article is published in line with "COPE (Committee on Publication Ethics) and PIE (Publication Integrity \& Ethics)". 


\section{INTRODUCTION}

Davies and Gray (2001) defined dental occlusion as the relation of the maxillary teeth and mandibular teeth as they meet in manduction or at inactivity. Occlusion in mastication is dynamic occlusion whereas contact of dentition once both jaws are occluded is static occlusion (Wassell et al., 2015). McDonald and Ireland (1998) emphasized that an idyllic closure is exceptional and it depends on the hypothetical concept of the dental structure. Hassan and Rahimah (2007) stated that this is a condition with the jaws of suitable sizes to each other and the teeth in proximate location in all three planes of space at rest. A perfect occlusion is seen with utmost occlusal pattern between the cusps of the teeth as the two arches interject.

Angle (1899) corroborated that normal occlusion happens when the superior and inferior molars contact where the mesiobuccal cusp of the superior molar occludes in the buccal groove of the inferior molar with the teeth in an orderly curve of occlusion. Typical occlusion is a tooth closure model in the scope of the established deviation of a perfect occlusion; one that does not confer functional and aesthetic issues. Malocclusion is deviation from the ultimate occlusion that is considered as aesthetically unsatisfactory; one characterized by discrepancy in the virtual position, dimensions of teeth and jaws (Houston et al., 1992).

Diverse sorts of occlusion were considered by Eveleth's (1972) who categorized dental closure model into: edge to edge characterized with alignment of the superior teeth and the inferior teeth, mild overbite diagnosed with overlap of the superior teeth a little on the inferior teeth, severe overbite an impression made with extreme overlap of the inferior teeth by the superior teeth, and negative overbite categorized when the inferior teeth overlap the superior teeth.

Schied and Woelfes (2007) affirmed that the upper incisors vertically overlap the incisal thirds of lower incisors and the size of the vertical overlap is known as an overbite. An overbite greater than three millimetres is termed a severe overbite. The incisors may well lack a vertical overlie and hence present with an edge-to-edge association with a gap between the incisal boundaries.

Literature exploration divulged lack of information on dental occlusion among the Urhobos in Delta State, Nigeria. This inquiry has information for use in orthodontics, anthropology and forensic science. The endeavour of this work was to consider varied dental occlusion patterns and explore gender variation in dental occlusion patterns amongst the Urhobo tribal cluster in Abraka, Nigeria.

\section{METHODOLOGY}

In conducting the study, the research assistant conformed to best practice in oral examinations whilst observing COVID-19 protocols. While wearing surgical face-mask and sanitized/sterile hand gloves, the assessment devices used in the study were duly disinfected before and after oral examination of each subject. Other Covid-19 protocols such as distance of two meters was maintained from every subject.

This inquisition which was done in December, 2020 is one that imbibed observation and cross-sectional examination. A cluster sample was engaged for data gathering. Ethical attention to detail was not ignored as authorization was gotten from the Human Anatomy Department of the Delta State University, Abraka. The sample comprised of three hundred and eighty-four (384) Urhobos subjects between 15-30 years of age. Specifically, 200 
(two hundred) subjects were females while 184 (one hundred and eighty-four) were males. Statistics on dental occlusion patterns were noted by instructing the subjects to bite, gulp saliva, occlude and open their oral cavities. The relationship between the superior and inferior teeth was noted as mild overbite, edge to edge bite, negative bite or severe overbite as pre-described by Eveleth (1972). Edge to edge occlusion form was the view for an occlusion when the incisal edges of the upper incisors contact the incisal edges of the lower incisors. Mild overbite is the impression in which the maxillary anterior teeth overlap the mandibular anterior teeth leaving a vertical overlay of the anterior teeth exactly 2-3 millimetres. Severe overbite is a condition with excess vertical overlap of the mandibular incisors (exceeding $3 \mathrm{~mm}$ or $30 \%$ percentage or $1 / 3 \mathrm{rd}$ the clinical crown height of the lower incisors) by the superior incisors. Negative overbite ensues once the inferior frontal teeth overlap the superior frontal teeth.

The statistics were analysed with SPSS version 23 and figures were illustrated by way of simple proportion and frequency. Chi-square test was utilized as an inferential statistical tool to check for the association involving gender and dental occlusion patterns; with significance established at $\mathrm{p}<.05$.

\section{RESULTS}

The gender grouping is such that a high proportion of the subjects were females (Figure 1). The gender gap is a portrayal of the male/female scattering in the assessed population. The commonness of mild overbite was the utmost $(168,43.4 \%)$ and after that was edge to edge bite $(146,38.2 \%)$. The severe overbite was displayed with rarity (Figure 2).

The sexual category of the different dental occlusion patterns as seen in the Urhobo tribal set of Delta State, Nigeria was scrutinized. Both masculine and feminine gender had high proportion of mild overbite: 72 (20.9\%) and $96(22.5 \%)$ correspondingly. Severe overbite was rarely observed among males $39(11.3 \%)$ and $31(7.1 \%)$ for females. Chi-square test did not expose notable gender variation since $\mathrm{p}$ was larger than .05 (Table 1).

The age grouping of the diverse dental occlusion patterns in the Urhobo ethnic set of Delta State, Nigeria was investigated. The 20-24years age category was the largest and thus had elevated percentages of mild overbite, edge- edge bite and severe overbite. Chi-square test did not bare remarkable age disparity in the dental occlusion as seen with a p-value greater than .05 (Table 2).

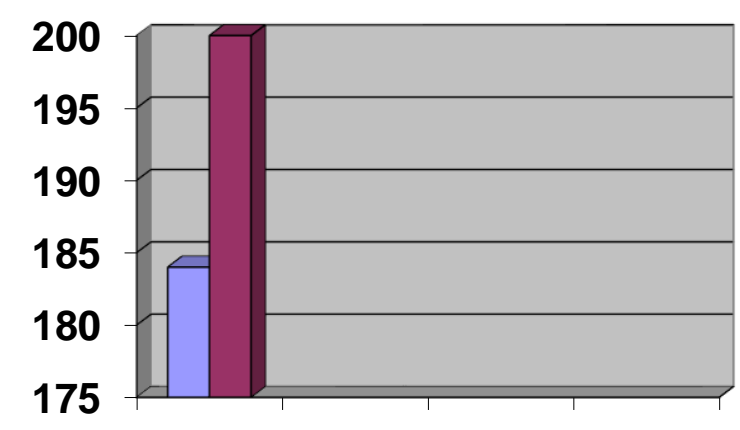

\section{Gender}

Figure 1: The gender of the Urhobo subjects 
$\square$ Edge-edge bite

a Mild overbite

$\square$ Severe overbite

$\square$ Negative overbite

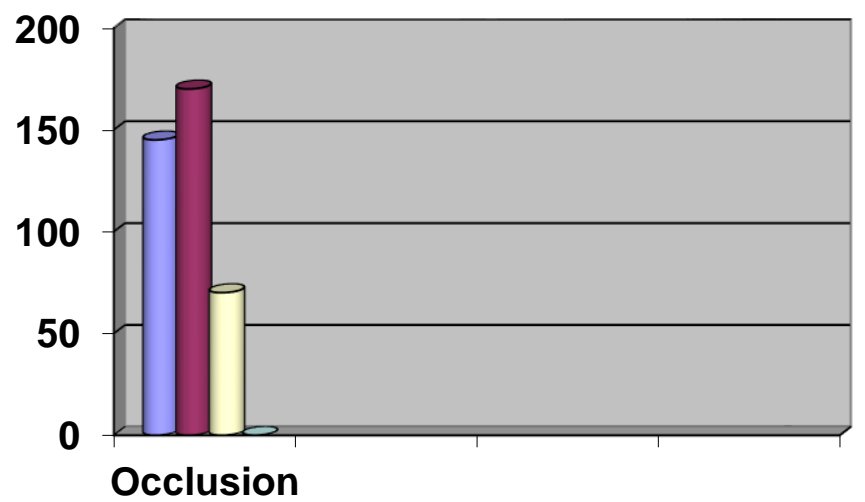

Figure 2: Patterns of dental occlusion among the Urhobo subjects

Table 1: Gender division in occlusion of teeth among the Urhobo subjects

\begin{tabular}{llllllll}
\hline \multirow{2}{*}{ Gender } & \multicolumn{5}{c}{ Dental Occlusion Model } \\
\cline { 2 - 6 } & Mild overbite & $\begin{array}{l}\text { Severe } \\
\text { overbite }\end{array}$ & $\begin{array}{l}\text { Negative } \\
\text { overbite }\end{array}$ & Edge-edge bite & Total & $\begin{array}{l}\text { Chi- } \\
\text { square }\end{array}$ & p-value \\
\hline Male & $72(20.9 \%)$ & $39(11.3 \%)$ & $0(0.0 \%)$ & $73(21.5 \%)$ & $184(53.7 \%)$ & & \multirow{2}{*}{3.96} \\
Female & $96(22.5 \%)$ & $31(7.1 \%)$ & $0(0.0 \%)$ & $73(16.7 \%)$ & $200(46.3 \%)$ & \multirow{2}{*}{3.96} \\
\hline Total & $168(43.4 \%)$ & $70(18.4 \%)$ & $0(0.0 \%)$ & $146(38.2 \%)$ & $384(100 \%)$ & & \\
\hline
\end{tabular}

Table 2: Association of age and patterns of dental occlusion

\begin{tabular}{|c|c|c|c|c|c|c|c|c|c|}
\hline \multirow{2}{*}{$\begin{array}{l}\text { Age } \\
\text { range } \\
\text { (years }\end{array}$} & \multicolumn{2}{|l|}{ Mild overbite } & \multicolumn{2}{|c|}{ Severe overbite } & \multicolumn{2}{|c|}{ Negative overbite } & \multicolumn{2}{|c|}{ Edge- edge bite } & \multirow[t]{2}{*}{ p-value } \\
\hline & Frequency & $\%$ & Frequency & $\%$ & Frequency & $\%$ & Frequency & $\%$ & \\
\hline $15-19$ & 22 & 40.00 & 10 & 18.18 & 0 & 0.00 & 23 & 41.82 & \\
\hline $20-24$ & 126 & 48.64 & 45 & 17.37 & 0 & 0.00 & 88 & 33.98 & .210 \\
\hline $25-30$ & 20 & 28.57 & 15 & 21.43 & 0 & 0.00 & 35 & 50.0 & \\
\hline
\end{tabular}

\section{DISCUSSION}

The reasons behind occlusal variation are centred on genetics and environmental influence (Corrucini, 1984; Proffit, 1986; McDonald \& Ireland, 1998). An ideal occlusion is one with the skeletal bases of the upper and lower jaws 
rendering precise sizes relative to each other and the teeth in exact relationship in the three planes of space at relaxation (McDonald \& Ireland, 1998).

The current academic toil disclosed the different tooth occlusion patterns among the Urhobo populace in Abraka, Delta State, Nigeria with the predominance of mild overbite, followed by edge-to-edge bite, and rarity of severe overbite. There was no notable gender variation in the dental occlusion patterns seen among the studied populace ( $p>.05$ ). These results are in concord with those of Anibor (2016); who saw a high rate of recurrence of mild overbite, followed by edge-to-edge bite, then negative overbite and rarely severe overbite with no notable gender variations from the research done in the Niger Delta region of Nigeria. Also, Singh and Sengupta (2004) stated that the mild overbite is preponderant in India. The Egyptians displayed more edge-to-edge sort of occlusion than mild overbite (El-Mangoury and Mostafa, 1990). Chinese grownups in Hong Kong were remarkable with 63.2\% cases of mild overbites and 31.3\% of severe overbites (Tang, 1994). An anthropometric inquisition of north-eastern Brazilians disclosed that $36.9 \%$ had normal occlusion (Eveleth, 1972).

This scrutiny did not trace any case of negative overbite. This is not in accord with the inquiry done in Northern Nigeria. The commonness of negative overbite in Hausa persons was less in males (1.8\%) than females (2.9\%). The regularity of mild overbite was the maximum (33.6\% in males, $32.6 \%$ in females) and next was edge to edge bite (13.3\% for males, $10.4 \%$ for females). Severe overbite was displayed rarely in both males (3.4\%) and females (2.1\%). However, just like the Urhobos in the current scrutiny, the Hausas did not divulge remarkable gender dissimilarity in their dental occlusion with p> .05 (Anibor, 2020).

Anibor (2019) examined Nigerians of the Igala ethnic faction who displayed predominance of mild overbite: $185(61.6 \%)$, then edge to edge bite: 61 (20.3\%), negative overbite: 42 (14\%) with severe overbite: 13 (4\%). No remarkable gender differences ( $p>.05)$ were noted in the prototypes of dental occlusion among the Igalas.

Nonetheless, the current conclusion contradicts that made by Anibor et al., (2014); they saw males with an elevated proportion of edge-to-edge bite, then mild overbite, negative overbite and rarely severe overbite in the Bini tribal set in Edo State. These academicians noted that females possessed a higher incidence of mild overbite, then edge-edge bite with an equivalent proportion of mild and severe overbite tooth closure prototypes.

The differences highlighted in this discussion could be ascribed to ethnic ties, racial or ecological factors. Confounders that may probably have affected the result of this inquisition include variation in skeletal growth, diet, parafunction and teeth drift.

\section{CONCLUSION}

This research has documented the dental occlusion patterns as seen in the Urhobo ethnic cluster in Abraka, Nigeria. The mild overbite was the prevalent category in the predominance of mild overbite, edge to edge bite with severe overbite and no notable gender variation was seen in the different dental occlusion patterns.

\section{CONFLICT OF INTEREST}

There is no conflict of interest to declare. 


\section{ACKNOWLEDGMENTS}

The author appreciates all the researchers whose articles are cited in this manuscript. The study subjects were cooperative and are particularly appreciated.

\section{REFERENCES}

Angle, E. H. (1899). Classification of malocclusion. Dental Cosmos.4: 248-264.

Anibor, E. (2019) Distribution of Tooth Oclussion Patterns among the Igalas in Kogi State, Nigeria. Nigerian Journal of Science and Environment. 17(1): 169-171.

Anibor, E., Edjomariegwe, O. \& Ajayi, A. (2014). Genetic and morphological traits among the Binis. International Journal of Current Research. 6 (11): 10222-10227.

Anibor, E. (2016). The Tooth Occlusion Pattern among the Niger Deltans in Nigeria.Nigerian Biomedical Science Journal. 12 (2): 10-12.

Anibor, E. (2020). Tooth Occlusion Pattern of the Hausas in Zaria, Nigeria. Anatomy Journal of Africa. 9 (1): $1723-1726$.

Corrucini RS (1984). An epidemiological transition in dental occlusion in world population. American Journal of Orthodontics and Dentofacial Orthopedics. 86: 419-426.

Davies, S., \& Gray, R.M.J. (2001). Occlusion: What is occlusion? British Dental Journal. 191 (5): 235-245.

Eveleth, P.B. (1972). An anthropometric study of North Eastern Brazilians. American Journal of Physical Anthropology.37: 223.

El-Mangoury, N. H., \& Mostafa. Y. A. (1990). Epidemiologic panorama of dental occlusion. The Angle Orthodontist. 60 (3):207-214.

Hassan, R., \& Rahimah, A.K. (2007). Occlusion, malocclusion and method of measurements-an overview. Archives of Orofacial Sciences. 2:3-9.

Houston, W.J.B., Stephens, C.D., \& Tulley, W.J.A. (1992). Textbook of Orthodontics, Great Britain: Wright; pp.1-13.

McDonald, F., \&Ireland, A.J (1998). Diagnosis of the Orthodontic Patient. New York: Oxford University Press.

Proffit, W. R., \& Fields, H. W. (2000). Contemporary Orthodontics. Chicago: Mosby Year Book, pp. 1-15.

Schied, R.C. (2007). Woelfe's Dental Anatomy: its relevance to dentistry (7th ed..; pp. 54-58). Williams and Wilkins, Baltimore.

Singh, J., \& Sengupta, S. (2004). Some Morpho-genetic and Behavioural Traits among the Assamese Sikhs. Anthropologist. 6 (4): 253-255.

Tang E.L. (1994). Occlusal features of Chinese adults in Hong Kong. Australian Orthodontic Journal. 13 (3):159163.

Wassell, R., Naru, A., Steele, J., \& Nohl, F. (2015). Applied occlusion (2nd ed.). London. 